(C) 2010. This manuscript version of Surface Tension of high Density Polyethylene (HDPE) in Supercritical Nitrogen: Effect of Polymer

Crystallization is made available under the CC-BY-NC-ND 4.0 license http://creativecommons.org/licenses/by-nc-nd/4.0/

This document is the accepted manuscript version of a published article. Published by Elsevier in the journal "Colloids and Surfaces A: Physicochemical and Engineering Aspects" volume 354, issues 1-3, page 347-352. doi:10.1016/j.colsurfa.2009.06.005.

\title{
Surface Tension of High Density Polyethylene (HDPE) in Supercritical Nitrogen: Effect of Polymer Crystallization
}

\author{
H. Wei ${ }^{1}$, R. B. Thompson ${ }^{2}$, C. B. Park ${ }^{3}$, and P. Chen ${ }^{1, *}$ \\ ${ }^{1}$ Departments of Chemical Engineering, and ${ }^{2}$ Physics and Astronomy, University of Waterloo, \\ 200 University Avenue, Waterloo, Ontario, Canada N2L 3GL, and ${ }^{3}$ Microcellular Plastics \\ Manufacturing Laboratory, Department of Mechanical and Industrial Engineering, \\ University of Toronto, 5 King's College Road, Toronto, Ontario, Canada M5S 3 G8 \\ *To whom correspondence should be addressed: Email: p4chen@uwaterloo.ca
}

KEYWORDS: surface tension; high density polyethylene; crystallinity; polymer foaming

\section{Abstract}

Surface tension of a polymer melt in a supercritical fluid is a principal factor in determining cell nucleation and growth in microcellular foaming. This work focuses on the surface tension of a crystalline polymer, high density polyethylene (HDPE), in supercritical nitrogen under various temperatures and pressures. The surface tension was determined by Axisymmetric Drop Shape Analysis-Profile (ADSA-P). The dependence of the surface tension on temperature and pressure, at temperatures above the HDPE melting point, $\sim 125^{\circ} \mathrm{C}$, was found to be similar to that of the amorphous polymer polystyrene (PS) in supercritical $\mathrm{CO}_{2}$, previously reported; i.e., the surface tension decreased with increasing temperature and pressure. Below $125^{\circ} \mathrm{C}$ and above $100^{\circ} \mathrm{C}$, HDPE underwent the process of crystallization, where the surface tension dependence on temperature was different from that above the melting point, and decreased with decreasing temperature. Differential Scanning Calorimetry (DSC) characterization of the polymer was carried out to reveal the process of HDPE crystallization and relate to this surface tension behavior. It was found that the amount of the decrease in surface tension was related to the rate of temperature change and hence the extent of polymer crystallization.

\section{Introduction}


Surface tension of polymers is one of the most important physicochemical parameters in many polymer engineering processes, such as microcellular foaming in supercritical fluids where the surface tension between the polymer melt and the fluid is a principal factor in determining cell nucleation and growth. ${ }^{1}$ Generally, low surface tension is desired in the polymer foaming process to increase the nucleation rate and produce small and uniform cells.

Among the methods of measuring surface tension, the pendant drop method is commonly used for polymers, liquid crystals, and other low-molar-mass liquids. ${ }^{3},{ }^{4}$ Despite the theoretical simplicity of the pendant drop method, experimental determination of the surface tension of a high viscosity polymer has been difficult, due to the handling of highly viscous polymer melts at high temperatures and pressures. ${ }^{5-11}$

The Axisymmetric Drop Shape Analysis (ADSA) approach relies on a numerical integration of the Laplace equation of capillarity to quantify surface tension. This numerical procedure applies to both sessile and pendant drops in shape analysis methods. ${ }^{12-14}$ Recently, ADSA has been used for determining polymer melt surface tension at high temperature and high pressure, ${ }^{15}$ e.g., the surface tension measurement of the amorphous polymer, polystyrene (PS), in supercritical $\mathrm{CO}_{2 .}{ }^{16,17}$

Surface tension of polymers in supercritical fluids varies with many parameters, e.g., temperature, pressure, and solubility of supercritical fluids. Recent reports ${ }^{16,17}$ showed several trends of the surface tension change with temperature and pressure for PS in supercritical $\mathrm{CO}_{2}$. In general, the surface tension decreases with increasing temperature and pressure. Self-consistent field theory (SCFT) calculations were used to explain these experimental trends. ${ }^{17}$

The degree of crystallinity of a polymer can have a large impact on polymer properties. It 
is known that polystyrene (PS) is a typical amorphous polymer, and high density polyethylene (HDPE) is a typical crystalline polymer. Both types of polymers are often used in polymer microcellular foaming processes. In molten phase, crystalline polymers and amorphous polymers may behave similarly. This is not the case in the solid state. When the temperature decreases below the melting point, amorphous polymers change into complete solids with disordered chain arrangements, but crystalline polymers would experience the process of crystallization: before a crystalline polymer becomes completely solid, it enters a viscoelastic state, where micro-crystals form and grow into regions of ordered chain arrangements within a continuous polymer melt. Surface tension measurement of polymers undergoing such transitions can help clarify the different behavior between amorphous and crystalline polymers. ${ }^{18,19}$ It has been found that the surface tension of amorphous polymers at temperatures below the melting point does not change significantly. But to date, no measurement on the surface tension of crystalline polymers has been made at temperatures below the melting point. It is plausible that the surface tension of a crystalline polymer may behave differently from that of an amorphous polymer, i.e., the crystalline polymer may respond to variations of temperature below the melting point. A follow up question would then be how temperature, or the rate of temperature change, affects the surface tension, as well as polymer crystallization. ${ }^{20-24}$

The primary purpose of this work is to establish an ADSA-based approach for evaluating the surface tension of the crystalline polymer high density polyethylene in supercritical nitrogen over a wide range of temperatures. The relationships of surface tension, solubility and crystallization with temperature and pressure will be investigated. The results will be compared with those of the amorphous polymer polystyrene, to show the difference between crystalline and amorphous polymers. 


\section{Experimental}

Materials. High Density Polyethylene (Nova Chemicals, Calgary, Canada) with a melt flow index (MFI) of $5.0 \mathrm{~g} / 10 \mathrm{~min}$ (ASTM D 1238) was used. Nitrogen (critical pressure 492 psi, critical temperature $-147^{\circ} \mathrm{C}$ ) at $99.99 \%$ purity was purchased from PRAXAIR (Danbury, CT, USA).

\section{Differential Scanning Calorimetry (DSC) Measurement: Melting and Crystallization}

of HDPE. DSC was used to study the melting behavior and crystallization of HDPE. A DSC Q2000 V24.3 instrument was adopted, calibrated for temperature and enthalpy before use, with the melting point of high purity lead. Nitrogen at $20 \mathrm{ml} / \mathrm{min}$ was used as the purge gas. The melting/crystallization process of HDPE was monitored at different temperature increasing/decreasing rates. For the melting process, the heating rates of $5 \mathrm{C} / \mathrm{min}$ and $30 \mathrm{C} /$ min were used. For the crystallization process, the cooling rates were $3 \mathrm{C} / \mathrm{min}, 30 \mathrm{C} / \mathrm{min}$, and $35 \mathrm{C} / \mathrm{min}$.

Surface Tension Measurement. The surface tension of HDPE in supercritical nitrogen was measured at different temperatures from 100 to $190^{\circ} \mathrm{C}$, within a wide range of pressures, from 500 to 1500 psi. To achieve these experimental conditions, a high-temperature and high-pressure sample cell was used. This optical viewing cell was connected with an electrical band heater and a pressure pump to simulate the polymer foaming conditions. The experimental setup was tested for its accuracy and reproducibility with a range of polymergas combinations, and the details of this setup and validation for the surface tension measurement were described in a recent publication. ${ }^{16}$

The technique of Axisymmetric Drop Shape Analysis-Profile (ADSA-P) was used for image analysis and parameter estimation. Surface or interfacial tensions were obtained by 
fitting the Laplace equation of capillarity to the acquired shape and dimensions of axisymmetric menisci. ${ }^{25}$ During this procedure, the density difference between HDPE and nitrogen was an input parameter, which was determined by the Sanchez and Lacombe (S-L) equation of state (EOS). ${ }^{26-28}$

Surface Tension of HDPE in $N_{2}$ above the Melting Point. This experiment was performed at eight different temperatures $125,130,140,150,160,170,180$ and $190{ }^{\circ} \mathrm{C}$ above the HDPE melting point, $\sim 125^{\circ} \mathrm{C}$, and three different pressures 500,1000 , and 1500 psi. The surface tension value of HDPE in supercritical nitrogen under various conditions was taken at its steady-state, when the change in surface tension was less than $0.0001 \mathrm{mJm}^{-2} \mathrm{~s}^{-1}$ for $1 \mathrm{~h}$. Thus the values obtained are regarded as equilibrium surface tensions. For each equilibrium surface tension reported, errors were on the order of $0.01 \mathrm{mJm}^{-2}$.

Steady-state Surface Tension of HDPE in $\mathrm{N}_{2}$ during Crystallization. The system pressure was controlled at 500,1000, or 1500 psi each time. The literature melting point for HDPE is around $125{ }^{\circ} \mathrm{C}$, above which the polymer is liquid, and below which polymer starts to crystallize until it turns completely solid. To investigate the effect of HDPE crystallization, the system was cooled from 150 to $100{ }^{\circ} \mathrm{C}$ in intervals of $10 \mathrm{C}^{\circ}$, during which the system was maintained at each condition for two hours, and the surface tension value was measured at its steady-state in each interval.

Dynamic Surface Tension of HDPE in $N_{2}$ during Crystallization. HDPE was first melted at above $130{ }^{\circ} \mathrm{C}$ and kept at that temperature for 8 hours until the surface tension reached equilibrium. Then the temperature was steadily dropped from $130{ }^{\circ} \mathrm{C}$ to $110{ }^{\circ} \mathrm{C}$. It took about 15 minutes for the band heater to complete this procedure. The system temperature was maintained at $110{ }^{\circ} \mathrm{C}$ afterwards for 1 hour. The time-dependent, or dynamic, surface tension during this entire process was measured until the system reached the final stead-state, where 
the surface tension reached equilibrium at $110^{\circ} \mathrm{C}$.

Correlation of Surface Tension Change with Temperature Change Rate. Two experiments were performed with different cooling procedures when crystallization of HDPE occurred. For the slower cooling rate experiment, the temperature was decreased from $150^{\circ} \mathrm{C}$ to $100^{\circ} \mathrm{C}$ stepwise in $10 \mathrm{C}^{\circ}$ intervals. The system was maintained at each interval until it reached steady-state and surface tension was measured. For the faster cooling rate experiment, the temperature was decreased from $150{ }^{\circ} \mathrm{C}$ to $100{ }^{\circ} \mathrm{C}$ steadily. The system was then maintained at $100{ }^{\circ} \mathrm{C}$ until it reached steady-state.

\section{Results and Discussion}

Melting Point of HDPE. The reported melting point of HDPE, $\sim 125^{\circ} \mathrm{C}$, is in the range of 120 to $130{ }^{\circ} \mathrm{C}$. To determine the melting point of the sample used in our experiments, differential scanning calorimetry (DSC) was used. Figure 1 shows the DSC results of HDPE melting under different heating rates. The polymer starts melting at around $110{ }^{\circ} \mathrm{C}$. The peak point at the slower heating rate is found to be around $125^{\circ} \mathrm{C}$, which is considered the melting point of the sample.

Surface Tension of HDPE in Nitrogen above the Melting Point. The equilibrium surface tension value of the HDPE melt in supercritical nitrogen was measured under various temperatures and pressures. Figure 2 shows the equilibrium surface tension at each temperature and pressure. The surface tension varies from $20.5 \mathrm{~mJ} / \mathrm{m}^{2}$ at $190{ }^{\circ} \mathrm{C}, 1500 \mathrm{psi}$, to $25.5 \mathrm{~mJ} / \mathrm{m}^{2}$ at $125{ }^{\circ} \mathrm{C}, 500 \mathrm{psi}$. It is apparent that at a given pressure, the surface tension decreases with increasing temperature; at a given temperature, the surface tension decreases with increasing pressure. The trend observed of the surface tension change with temperature is consistent with that of $\mathrm{Wu}$, where a linear relationship between surface tension and 
temperature was proposed for polyethylene melts. ${ }^{29}$ However, in our experiments, pressure was an additional variable. To find how surface tension is related with both temperature and pressure, a second-order linear regression model for the surface tension $\gamma$ was proposed and tested against the experimental results.

$\gamma=31.7534-0.04611 \mathrm{~T}-0.00165 \mathrm{P}$

$\left(125^{\circ} \mathrm{C}<\mathrm{T}<190^{\circ} \mathrm{C}, 500 \mathrm{psi}<\mathrm{P}<1500 \mathrm{psi}\right)$

where the surface tension of HDPE in supercritical $\mathrm{N}_{2}$ is in $\mathrm{mJ} / \mathrm{m}^{2}$, the temperature $\mathrm{T}$ in ${ }^{\circ} \mathrm{C}$, and the pressure $\mathrm{P}$ in psi. Table 1 shows analysis of variance, or ANOVA, indicating the validity of the regression model: the observed F-value is larger than the tabulated F-value at the $95 \%$ confidence level. In Table 2 , the validity of each parameter in the second order equation was also examined by using the t-test: all observed t values are greater than the tabulated t-value at the $95 \%$ confidence level. This result shows the second-order term in $\mathrm{T}$ or $\mathrm{P}$ and the interaction term in TP are absent; statistically, $\gamma$ is linearly related to T and $\mathrm{P}$.

From Eq. (1), the following equations can be derived:

$\frac{\partial \gamma_{H D P E}}{\partial P}=-1.65 \times 10^{-3}$
$\frac{\partial \gamma_{H D P E}}{\partial T}=-4.61 \times 10^{-2}$

The trends of $\gamma$ with $\mathrm{T}$ and $\mathrm{P}$ seem to be consistent with that of the surface tension of polystyrene (PS) in supercritical $\mathrm{CO}_{2}{ }^{17}$, where

$$
\begin{aligned}
& \frac{\partial \gamma_{P S}}{\partial P}=-1.00 \times 10^{-2} \\
& \frac{\partial \gamma_{P S}}{\partial T}=-5.59 \times 10^{-2} \\
& \frac{\partial^{2} \gamma_{P S}}{\partial T P}=2.60 \times 10^{-5}
\end{aligned}
$$


There is one different trend for HDPE in $\mathrm{N}_{2}$ from PS in $\mathrm{CO}_{2}$, Eq. (6): the interaction term in TP for PS in $\mathrm{CO}_{2}$ shows the rate of the surface tension change of PS with temperature increases with increasing pressure, while this term is absent for HDPE in $\mathrm{N}_{2}$ indicating the rate of the surface tension change of HDPE with temperature does not change much.

The Change of Solubility with Temperature and Pressure. Besides surface tension, the solubility of a gas in a polymer is also an important parameter in determining the foaming quality. By examining the change of solubility, as well as surface tension, with the change of temperature and pressure, one can see that both surface tension and solubility depend on temperature and pressure.

First, if the temperature is maintained, as the pressure is increased, the solubility of $\mathrm{N}_{2}$ in HDPE increases and the surface tension decreases. This is reasonable when considering the fact that an increase in gas-phase pressure will likely induce more gas dissolution into the liquid phase. ${ }^{16}$ Comparing the surface tension dependence on pressure, from Eqs. (2) and (4), it is found the surface tension drops more with the same amount of increase in pressure for PS in $\mathrm{CO}_{2}$ than for HDPE in $\mathrm{N}_{2}$. Correspondingly, the solubility dependence on pressure of $\mathrm{CO}_{2}$ in PS is stronger than that of $\mathrm{N}_{2}$ in HDPE, which can be observed from Eqs. (7) and (8) derived from the solubility data: ${ }^{30-31}$

$$
\begin{aligned}
& \frac{\partial C_{N_{2}}}{\partial P}=7.5 \times 10^{-6} \\
& \frac{\partial C_{C_{2}}}{\partial P}=2.86 \times 10^{-5}
\end{aligned}
$$

From the experimental results, the surface tension at different temperatures begins to converge at higher pressures for PS in $\mathrm{CO}_{2}$, while this phenomenon is not observed for HDPE in $\mathrm{N}_{2}$. Figure 3 shows that the solubility of $\mathrm{N}_{2}$ in HDPE increases slightly with increasing temperature, while to the contrary, the solubility for $\mathrm{CO}_{2}$ in PS decreases with 
increasing temperature. For $\mathrm{CO}_{2}$ in PS, there are two competing factors affecting the solubility: an increase in pressure tends to increase the solubility, while an increase in temperature tends to decrease it. Thus, pressure and temperature together determine the solubility of $\mathrm{CO}_{2}$ in PS. Based on the same argument, the rate of the surface tension change of PS with temperature decreases at higher pressures. ${ }^{16}$ For the case of $\mathrm{N}_{2}$ in HDPE, increases in both pressure and temperature tend to increase the solubility. Correspondingly, the rate of the surface tension change of HDPE with temperature does not decrease at higher pressures; note there is no interaction term for HDPE.

Surface Tension of $\mathrm{HDPE}$ in $\mathbf{N}_{2}$ accompanied by Crystallization. The results of experiments are shown in Figure 4. With decreasing temperature, the surface tension first increases until temperature reaches the melting point of $\mathrm{HDPE}, \sim 125^{\circ} \mathrm{C}$, and then it drops sharply with further decreasing temperature. The surface tension eventually approaches a plateau, around $20 \mathrm{~mJ} / \mathrm{m}^{2}$ at $110^{\circ} \mathrm{C}$ for a pressure of 500 psi. The Differential Scanning Calorimetry results of melting HDPE show that the polymer starts to melt at $110{ }^{\circ} \mathrm{C}$. This may explain why the surface tension of HDPE does not change any further when temperature goes under $110^{\circ} \mathrm{C}$, since the polymer becomes completely solid at this point and below. Note, surface tension of a PS melt in $\mathrm{CO}_{2}$ increases with decreasing temperature, and it does not change any further when temperature reaches $100{ }^{\circ} \mathrm{C}$, which is the glass transition temperature of PS. If comparing the surface tension results of these two polymers under their melting points, one may consider that the difference is due to the fact that polystyrene is an amorphous polymer, while HDPE is a crystalline polymer. Once the temperature goes below $100{ }^{\circ} \mathrm{C}$, PS solidifies and hence surface tension detected by ADSA would not change any further. This is similar to the case of HDPE under $110^{\circ} \mathrm{C}$. However, different from PS, there is a decrease in surface tension between $110^{\circ} \mathrm{C}$ and $125^{\circ} \mathrm{C}$ observed for HDPE, which is the 
period for crystallization. During the HDPE crystallization, there are micro-crystals nucleated that immerse in the polymer melt.

Polymer crystallization can take time and occur with a range of temperatures, during which the polymer behaves viscoelastically with a high elasticity characteristic. When temperature is decreased to induce crystallization, small crystals form and grow. These crystals may act as, or be considered, nanoparticles, in the polymer melt. It is possible that nanoparticles in polymer melts decrease the surface tension. It is known that the presence of nanoparticles in polymer melts enhances the polymer interaction with foaming agents, which leads to an improved foaming quality. ${ }^{32,} 33$ Thus, it may not be surprising that the surface tension decreases with decreasing temperature, when accompanied by the polymer crystallization.

\section{Correlation of Surface Tension Decrease with Temperature Change Rate. The} dynamic surface tension was measured when temperature was steadily dropped from $130{ }^{\circ} \mathrm{C}$ to $110{ }^{\circ} \mathrm{C}$, passing through its melting point $125^{\circ} \mathrm{C}$. The results are shown in Figure 5. The surface tension first increases with decreasing temperature and then drops sharply, approaching a plateau around $23.3 \mathrm{~mJ} / \mathrm{m}^{2}$. During this dynamic process, the increase in surface tension with decreasing temperature at the beginning is due to the fact that the temperature is still above the HDPE melting point. Once the temperature goes below this melting point, HDPE starts to crystallize and thus there is a decrease in surface tension until it reaches a plateau. To recall the experiments discussed in the last section, where the temperature was dropped stepwise, the surface tension decreased to $20.0 \mathrm{~mJ} / \mathrm{m}^{2}$. But in the current continuous decrease in temperature, the surface tension only decreased to $23.3 \mathrm{~mJ} / \mathrm{m}^{2}$. An obvious difference in temperature change is the rate of decrease in temperature. It is concluded that the faster the temperature change rate, the smaller change in surface tension. 
Figure 6 is the DSC results of HDPE crystallization under different temperature change rates. It shows that if the polymer is cooled down slowly, HDPE has enough time to crystallize, and thus more crystals can form and grow. This in turn results in a greater decrease in surface tension. To the contrary, if the temperature change rate is high, HDPE does not have enough time to crystallize before becoming completely solid, corresponding to a broader peak at a lower temperature. Thus, less of a decrease in surface tension is observed.

Two experiments were conducted at different temperature change rates to confirm this argument. The results are shown in Figure 7. The surface tension of HDPE in nitrogen at different temperature change rates was measured. The solid spots were the surface tension values obtained at the slower temperature change rate, while the open spots were obtained at the faster temperature change rate. It is seen that the faster a temperature change rate, the less a decrease in surface tension. Figure 8 shows the appearance of the polymer after the process of crystallization at different temperature change rates. It is known that polymers with different degrees of crystallinity show different degrees of transparence. ${ }^{18}$ Figure 8 (a) is the HDPE sample that experienced a fast temperature change rate; it is more transparent, indicating a lower extent of crystallinity. Figure 8 (b) is the sample that experienced a slow temperature change rate; it is more translucent, indicating a higher degree of crystallinity. These results support the above argument that the amount of decrease in surface tension is related to the rate of temperature change and the extent of polymer crystallization.

\section{Conclusions}

The surface tension dependence of the crystalline polymer HDPE in supercritical $\mathrm{N}_{2}$ on temperature and pressure was obtained experimentally and compared with that of the amorphous polymer PS in $\mathrm{CO}_{2}$. At temperatures above the melting point, the trends of the 
surface tension change with temperature and pressure of HDPE are similar to those of PS, i.e., the surface tension decreases with increasing temperature and pressure. When crystallization of HDPE occurs, the surface tension decreases with decreasing temperature. During crystallization, polymer micro-crystals form and may act like nanoparticles in polymer melts, reducing the surface tension. It is found that the amount of decrease in surface tension is related with the temperature change rate, and hence the rate of crystallization; the surface tension decreases more with a slower temperature change rate, or a higher degree of crystallinity.

\section{Acknowledgments}

This work is supported by NSERC and CRC programs of Canada. The authors thank Research in Motion for the use of equipment and Dr. Bev Christian for advice and suggestions for many aspects of the research.

\section{Reference}

(1) Myers D. Surfaces, Interfaces, and Colloids: Principles and Applications; VCH Publishers: New York, 1991.

(2) Nishioka, K.; Kusaka J. Chem. Phys. 1992, 96 (7), 5370-5376.

(3) del Rio, O. I.; Neumann, A. W. J. Colloid Interface Sci. 1997, 196, 136-147.

(4) Lahooti, S.; Rio, O. I.; Cheng, P.; Neumann, A. W. Applied Surface Thermodynamics; Neumann, A. W., Spelt, J. K., Eds.; Marcel Dekker: New York, 1996.

(5) Demarquette, N. R.; Kamal, M. R. Polym. Eng. Sci. 1994, 34 (24),1823-1833.

(6) Roe, R.-J.; Bacchetta, V. L.; Wong, P. M. G. J. Phys. Chem. 1967, 71, 4190.

(7) Wu, S. J. Phys.Chem. 1970, 74, 632. 
(8) Wu, S. Polymer Interface and Adhesion; Marcel Dekker: New York, 1982.

(9) Demarquette, N. R.; Kamal, M. R. Polym. Eng. Sci. 1994, 34, 1823.

(10) Morita, A. T.; Carastan, D. J.; Demarquette, N. R. Colloid Polym. Sci. 2002, 280, 857.

(11) Xue, A.; Tzoganakis, C.; Chen, P. Polym. Eng. Sci. 2004, 44, 18.

(12) Cheng, P.; Li, D.; Boruvka, L.; Rotenberg, Y.; Newmann, A. W. Colloids Surf. 1990, 43, 151-167.

(13) Susnar, S. S.; Hamza, H. A.; Newmann, A. W. Colloids Surf. 1994, 89, 169-180.

(14) Cheng, P.; Neumann, A. W. Colloids Surf. 1992, 62, 297-305.

(15) Li, H.; Lee, L. J.; Tomasko, D. L. Ind. Eng. Chem. Res. 2004, 43, 409.

(16) Park, H.; Park, C. B.; Tzoganakis, C.; Tan, K. H.; Chen, P. Ind. Eng. Chem. Res. 2006, $45,1650-1658$.

(17) Park, H., Thompson, R.B., Lanson, N., Tzoganakis, C., Park, C.B. and Chen, P. J. Phys. Chem. B 2007, 111, 3859-3868.

(18) Zeus Industrial Products, Inc. Technical Whitepaper 2007.

(19) Wunderlich, B. J. Phys.Chem.1958 296.

(20) Jürgen, E.K. Schawe Thermochimica Acta 2007461 145-152.

(21) Wunderlich, B. Macromolecular Physics vol. 1, Academic Press, New York, 1973.

(22) Wunderlich, B. Macromolecular Physics vol. 3, Academic Press, New York, 1980.

(23) Zachmann, H.G. Fortschr. Hochpolym. Forsch. 19643581.

(24) Pijpers, T.F.J., Mathot, V.B.F., Goderis, B., Scherrenberger, R.L., and vander Vegte, E.W. Macromolecules 2002333601.

(25) Andreans, J. M.; Hauser, E. A.; Trucker, W. B. J. Phy. Chem. 1938, 42, 1001-1019.

(26) Xue, A.; Tzoganakis, C.; Chen, P. Polym. Eng. Sci. 2004, 44, 18-27.

(27) Li, H.; Lee, L. J.; Tomasko, D. L. Ind. Eng. Chem. Res. 2004, 43, 509-514. 
(28) Sato, Y.; Takikawa, T.; Takishima, S.; Masuoka, H. J. of Supercrit. Fluids 2001, 19, 187-198.

(29) Wu, S. Journal of Colloid and Interface Science, 1969312.

(30) Yoshiyuki S., Masashi Y., Fujiwara, K., Takishima, S., and Masuoka, H. Fluid Phase Equilibria 1996125 129-138.

(31) Yoshiyuki S., Fujiwara, K., Takikawa, T., Sumarno, Takishima, S., and Masuoka H. Fluid Phase Equilibria 1999162 261-276.

(32) Lee, Y.H., Park, C.B., Wang, K.H., and Lee, M.H. Journal of Cellular Plastics 200541 487-502.

(33) Lee, Y.H., Park, C.B., Sain, M., Kontopoulou, M., and Zheng, W.G., Journal of Applied Polymer Science, 2007105 1993-1999

\section{Caption of Figures}

Figure 1. DSC results of the melting process of HDPE at different heating rates: $5{ }^{\circ} \mathrm{C} / \mathrm{min}$ (solid symbols), $30^{\circ} \mathrm{C} / \mathrm{min}$ (open symbols).

Figure 2. The equilibrium surface tension of HDPE in $\mathrm{N}_{2}$ at various temperatures $(125,130$, $140,150,160,170,180,190^{\circ} \mathrm{C}$ ) and pressures $(500,1000,1500 \mathrm{psi})$ above the HDPE melting point $\left(125^{\circ} \mathrm{C}\right)$.

Figure 3. Solubility of gas in polymer at various temperatures $\left(150,190,230{ }^{\circ} \mathrm{C}\right)$ and pressures $(500,1000,1500 \mathrm{psi})$ : the solid symbols present the solubility data of $\mathrm{N}_{2}$ in HDPE, and open symbols present the solubility data of $\mathrm{CO}_{2}$ in PS. 
Figure 4. The equilibrium surface tension of HDPE in nitrogen at various temperatures and pressures $(500,1000,1500 \mathrm{psi})$ through its crystallization region. The system was cooled from 150 to $100{ }^{\circ} \mathrm{C}$ in intervals of $10 \mathrm{C}^{\circ}$, during which the system was maintained at each condition for two hours, and the surface tension value was measured at its steady-state.

Figure 5. Surface tension of the HDPE melt in supercritical nitrogen at different temperatures as a function of time when the temperature changes from $130{ }^{\circ} \mathrm{C}$ steadily to 110 ${ }^{\circ} \mathrm{C}$. It took $\sim 15$ minutes for the band heater to complete this procedure. The temperature was then maintained at $110^{\circ} \mathrm{C}$ for 1 hour.

Figure 6. DSC results for the crystallization process of HDPE at different cooling rates: $3{ }^{\circ} \mathrm{C} /$ $\min , 30^{\circ} \mathrm{C} / \mathrm{min}, 35^{\circ} \mathrm{C} / \mathrm{min}$.

Figure 7. The surface tension of HDPE in Nitrogen at different temperature change rates: the solid symbols indicate experiments at slower crystallization cooling speeds. The open symbols indicate experiments at faster crystallization cooling speeds (see the Experimental section).

Figure 8. The images of HDPE samples under 40 times microscope after the sample underwent different crystallization processes: (a) fast crystallization; (b) slow crystallization. 
TABLE 1: ANOVA (Analysis of Variance) Table for a Second-Order Linear Regression Model

\begin{tabular}{lccc}
\hline & $\begin{array}{c}\text { sum of } \\
\text { square(SS) }\end{array}$ & $\begin{array}{c}\text { degree of } \\
\text { freedom }\end{array}$ & $\begin{array}{c}\text { mean } \\
\text { square(MS) }\end{array}$ \\
\hline $\begin{array}{l}\text { regressio } \\
\mathrm{n}\end{array}$ & 27.35163 & 3 & 13.67581 \\
residual & 0.45054 & 17 & 0.02503 \\
total & 27.80217 & 20 & \\
& $\mathrm{~F}_{\text {obs }}=546.4 ; \mathrm{F}_{3,17,0.05}=3.2$, R-Square $=0.98$
\end{tabular}

TABLE 2: t-Test for Evaluating Each Parameter of the Proposed Second-Order Linear Regression Model 


\begin{tabular}{cccc}
\hline parameters & coefficients & standard error & $\mid \mathrm{t}$-value $\mid$ \\
\hline intercept & 31.75343 & 0.29090 & 109.15406 \\
$\mathrm{~T}$ & -0.04611 & 0.00173 & 26.71155 \\
$\mathrm{P}$ & -0.00165 & $8.46 \mathrm{E}-5$ & 19.47416
\end{tabular}

$\mathrm{T}_{0.025,17}=2.11$

Figure 1.

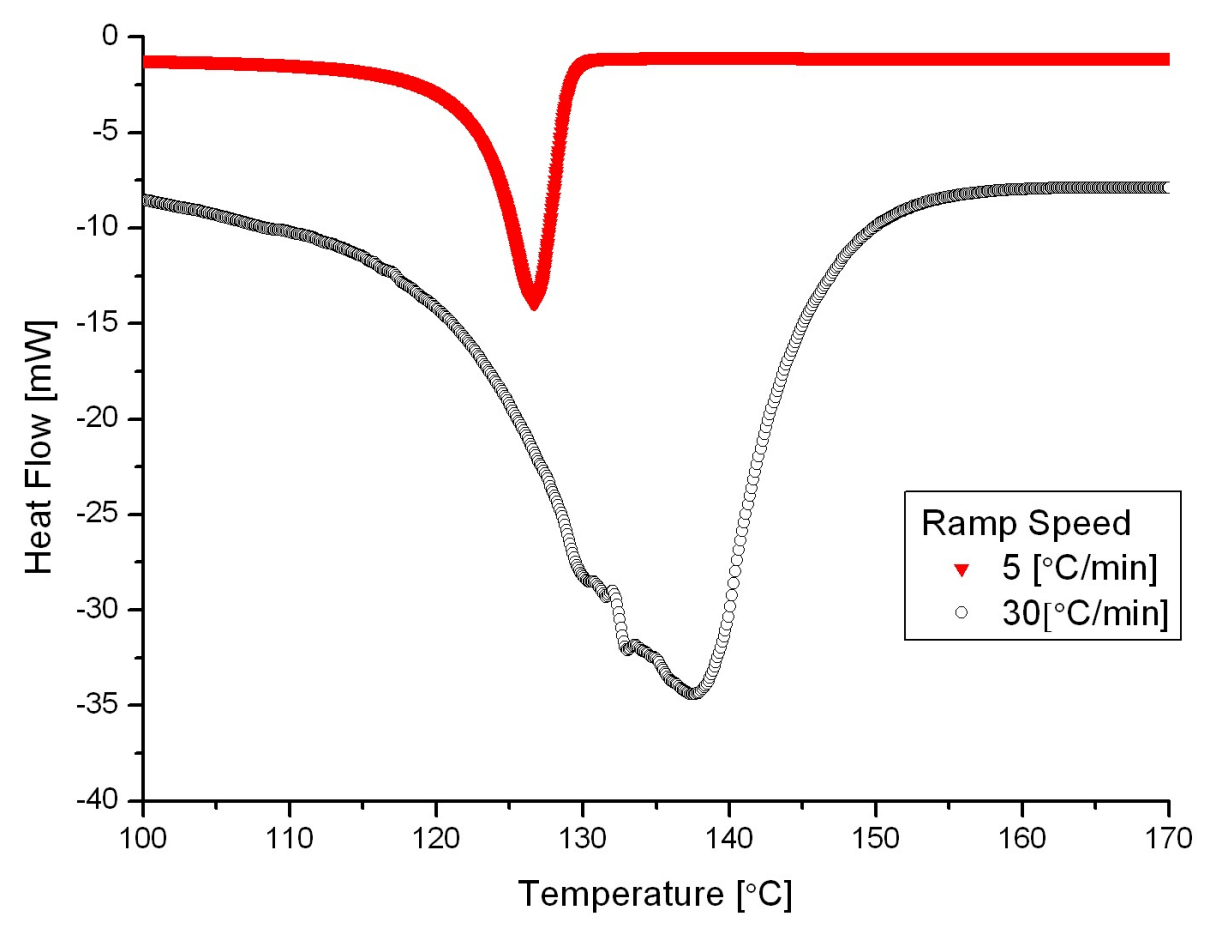


Figure 2.

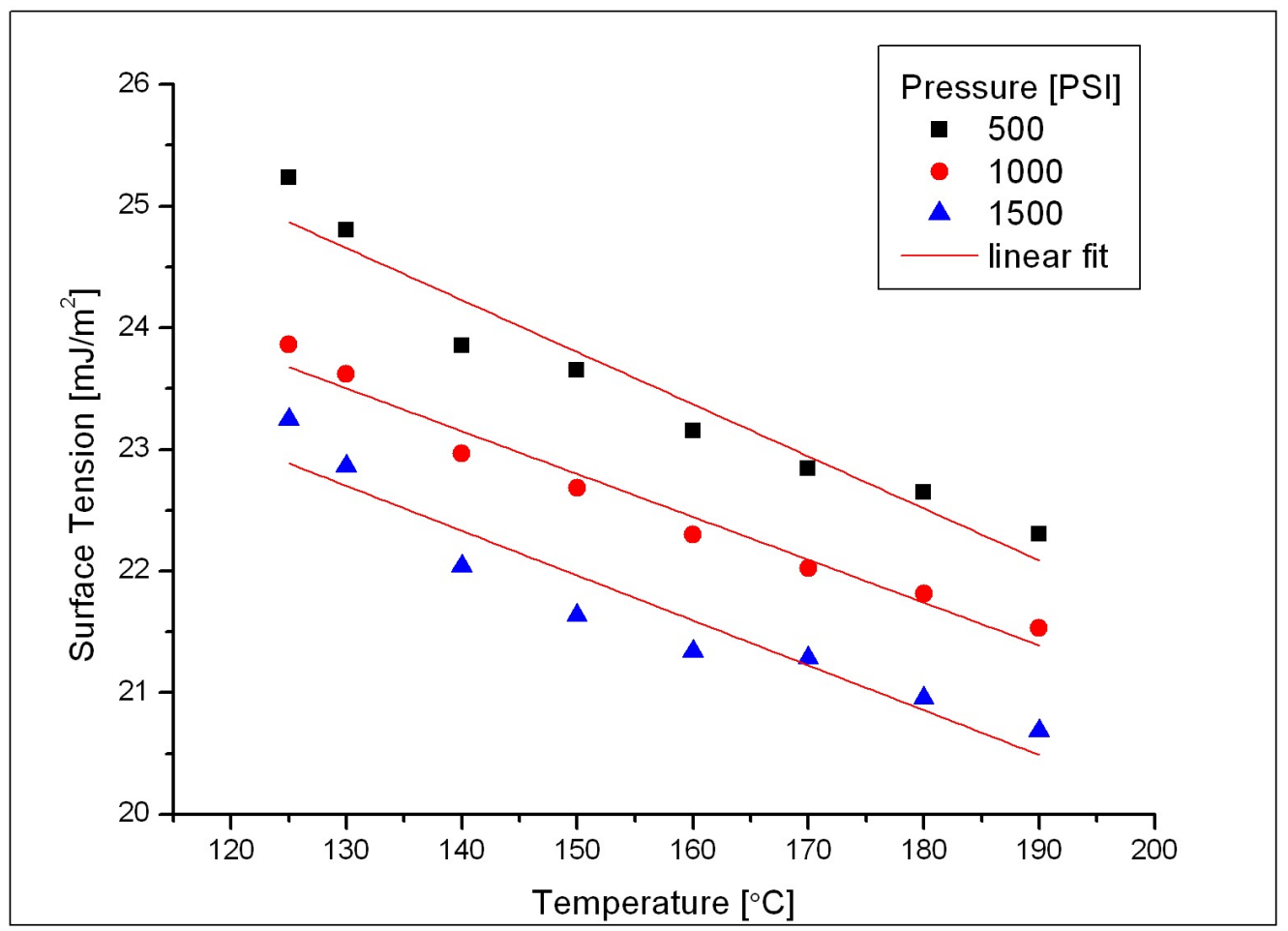


Figure 3.

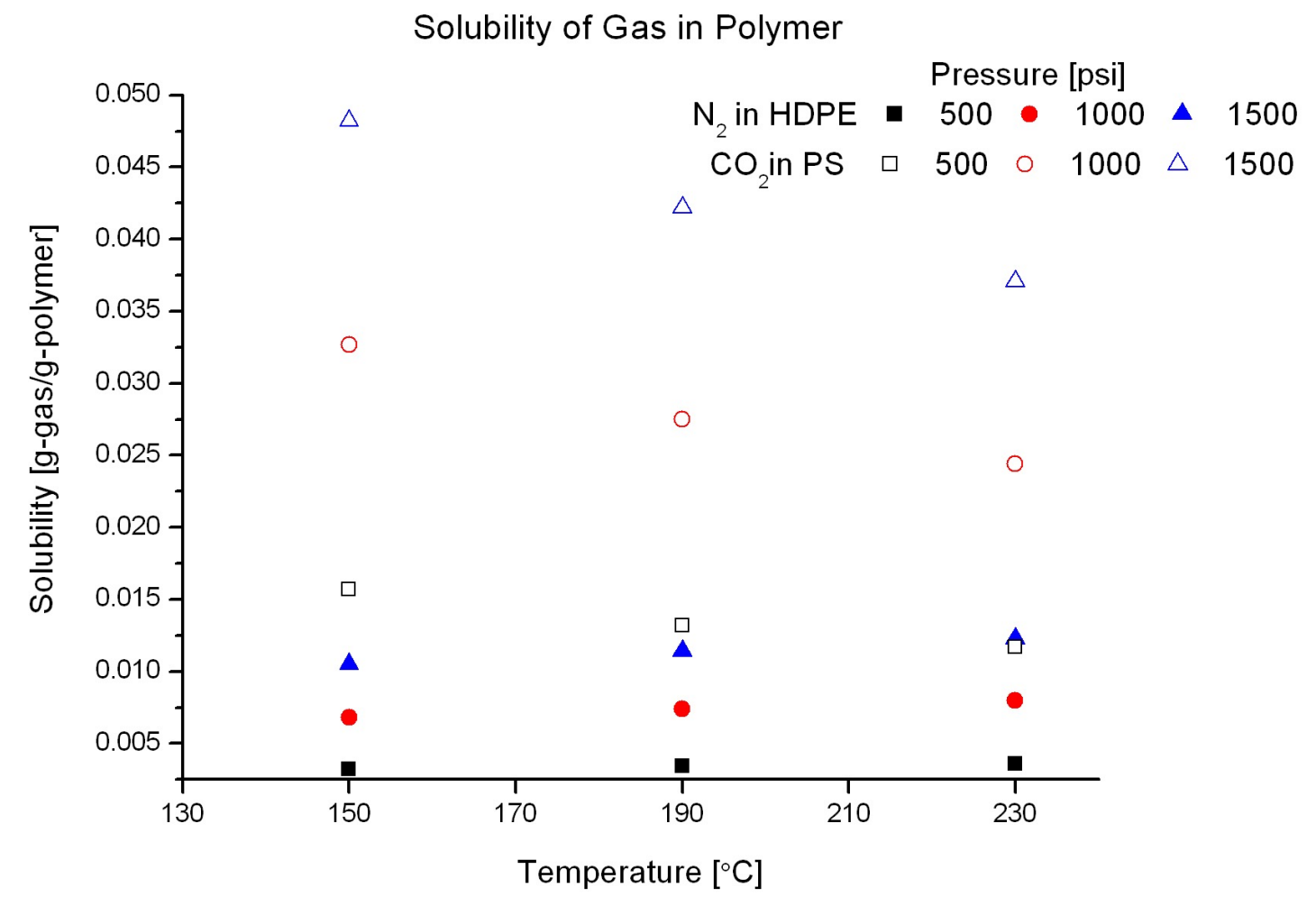


Figure 4.

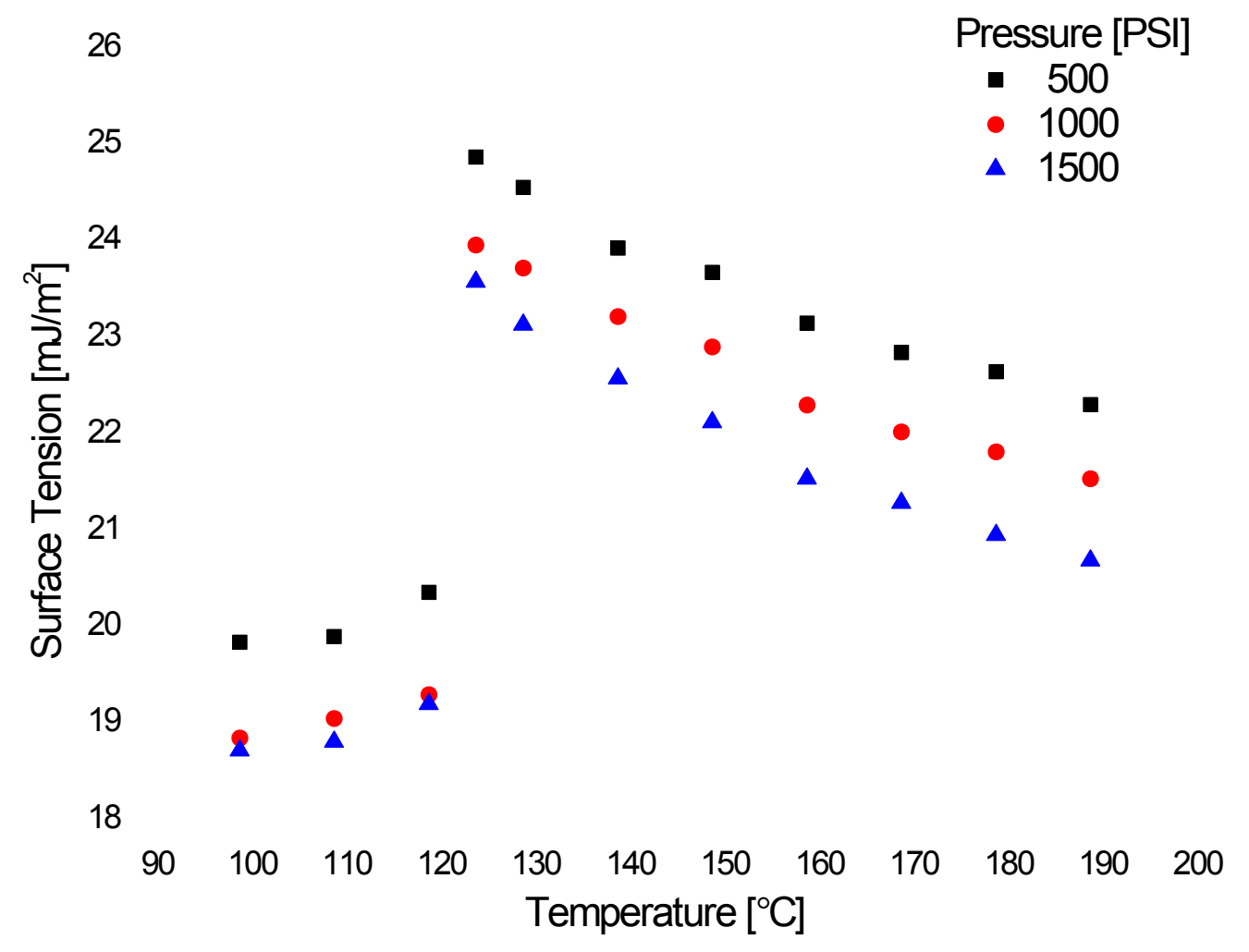


Figure 5.

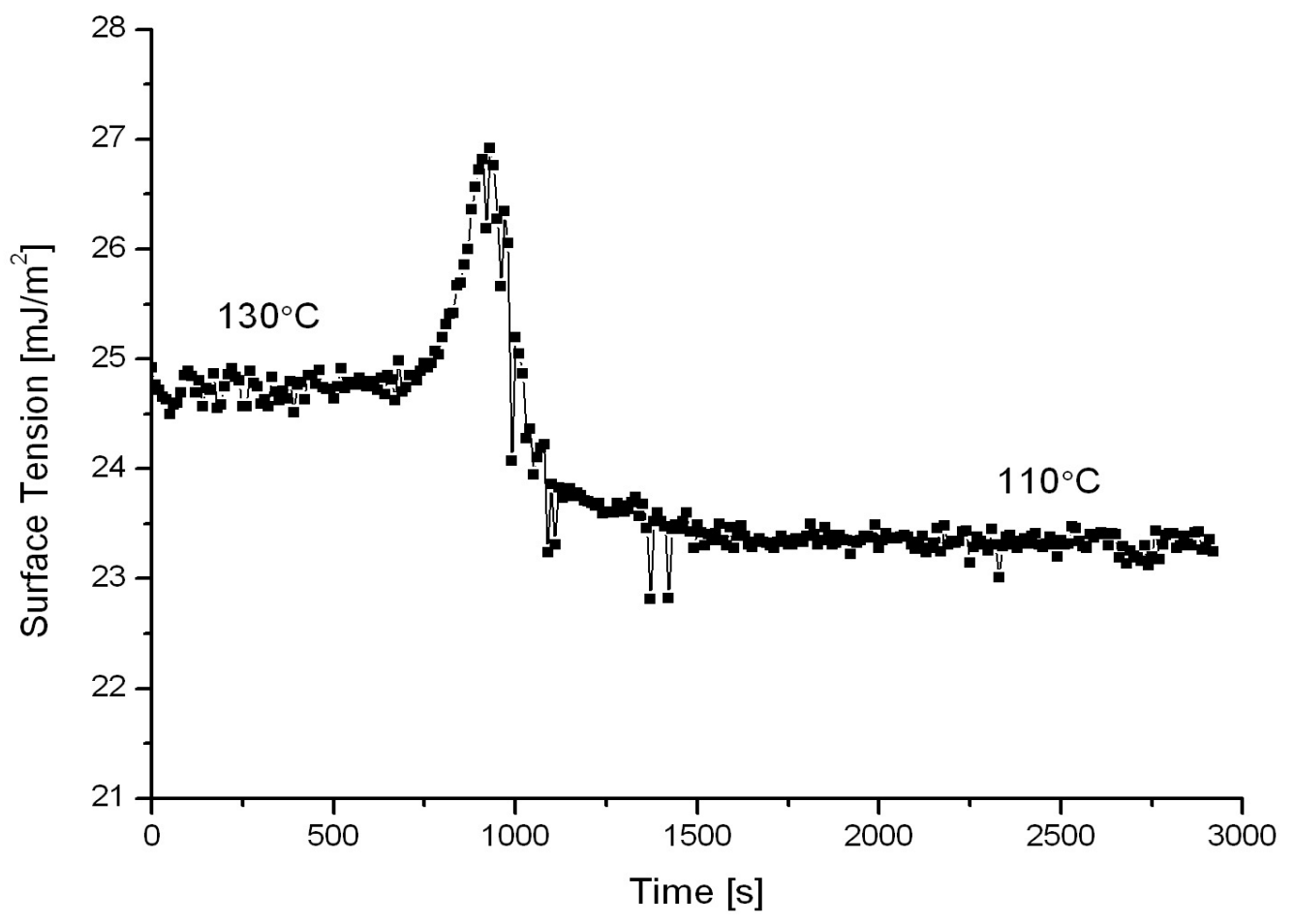

Figure 6. 


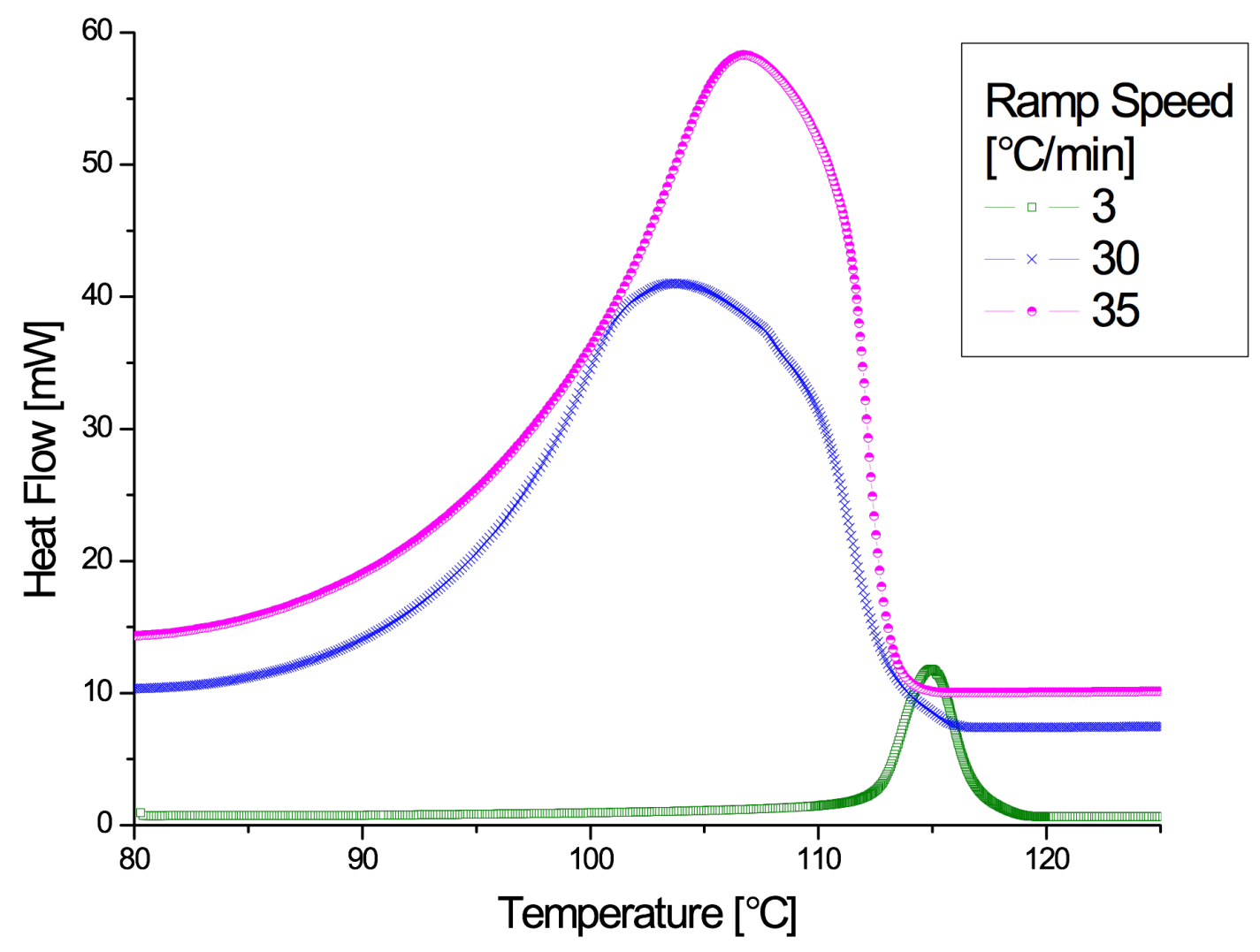

Figure 7. 


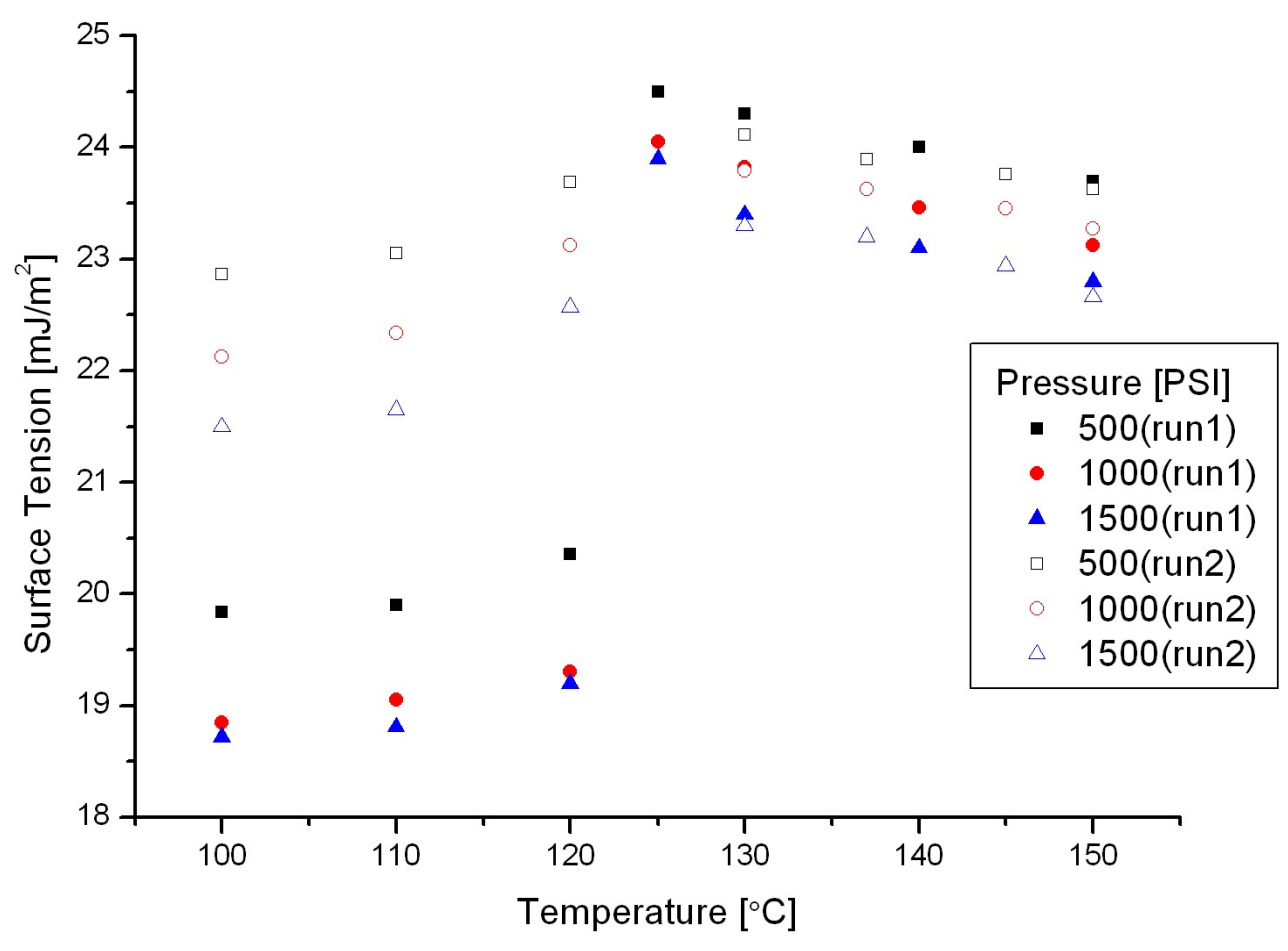

Figure 8. 
